Original Article

\title{
Clinical characteristics and factors associated with in hospital mortality of convulsive status epilepticus in adult patients admitted to neurointensive care unit
}

\author{
Sudhindra Vooturi ${ }^{a}$, Sita Jayalakshmi ${ }^{a, *}$, Sambit Sahu ${ }^{b}$, \\ Surath Mohandas ${ }^{a}$ \\ ${ }^{a}$ Department of Neurology, Krishna Institute of Medical Sciences, Secunderabad 500003 , \\ Andhra Pradesh, India \\ ${ }^{\mathrm{b}}$ Department of Critical Care, Krishna Institute of Medical Sciences, Secunderabad 500003 , \\ Andhra Pradesh, India
}

\section{A R T I C L E I N F O}

Article history:

Received 4 November 2013

Accepted 2 May 2014

Available online 24 May 2014

Keywords:

Adult patients

Status epilepticus

Outcome

Mortality

\begin{abstract}
A B S T R A C T
Background: Status epilepticus (SE) is a common neurological emergency; convulsive SE has a distribution with peaks in children and elderly than adult population.

Aim: To determine the clinical characteristics and factors associated with in hospital mortality in adult patients admitted to the neurointensive care unit (NICU).

Methods: A retrospective analysis of the clinical characteristics and outcome of adult patients (aged 18 years and above, below 60 years) with CSE admitted into the NICU was performed. The outcome was classified as alive or death in NICU. The differences between the alive and dead patients for data collected were analyzed using $t$ tests and chi-square test for continuous and categorical variables respectively. Spearman correlations were used to analyze association between the variables, where $r>0.3$ and $p<0.05$ were considered significant.

Results: A total of 105 adult patients formed the inclusion criteria and were included for data analysis. Forty two out of the 105 patients were women. Sixty one (58\%) of the 105 patients had acute symptomatic etiology while $17.1 \%$ patients were known epileptics; acute symptomatic etiology increased risk of mortality 5.28 times (95\% confidence interval (CI): $1.44-19.35)(p=<0.01)$. Thirty eight $(36.1 \%)$ patients progressed to refractory SE. The mortality in the entire cohort was $19 \%$. Complications of prolonged mechanical ventilation and refractory status epilepticus showed strong and significant association with mortality $(r>0.300 ; p<0.0001)$. Mortality was significantly higher in patients with acute symptomatic etiology and than other etiologies $(85.0 \%$ vs $54.1 \% ; p=0.011)$.

Conclusion: Acute symptomatic etiology was the most common cause of SE in adults. While requirement for mechanical ventilation and refractory SE were the major factors
\end{abstract}

\footnotetext{
* Corresponding author. Department of Neurology, Krishna Institute of Medical Sciences, 1-8-31/1, Minister Road, Secunderabad 500 003, Andhra Pradesh, India. Tel.: +91 9618117118; fax: +91 4027840980.

E-mail addresses: sita_js@hotmail.com, sita.js@gmail.com (S. Jayalakshmi). http://dx.doi.org/10.1016/j.ijep.2014.05.001

2213-6320/Copyright @ 2014, Indian Epilepsy Society. Published by Reed Elsevier India Pvt. Ltd. All rights reserved.
} 
associated with mortality, acute symptomatic etiology increased the risk of mortality in adult patients with SE.

Copyright @ (2014, Indian Epilepsy Society. Published by Reed Elsevier India Pvt. Ltd. All rights reserved.

\section{Introduction}

Status epilepticus (SE) in adults is defined as continuous, generalized convulsive seizure that lasts for more than $5 \mathrm{~min}$ or two or more seizures during which the patient doesn't regain consciousness. ${ }^{1}$ Of the various types of $\mathrm{SE}$, convulsive status epilepticus (CSE) is reported in up to 27 per every 100,000 adults. ${ }^{2}$ Convulsive SE has a distribution with peaks in children and elderly. Nevertheless, a considerable percentage of all patients with CSE are aged between 18 and 60 years. Nearly one third of these patients get refractory to treatment with benzodiazepine and one anti-epileptic drug (AED), which is named as refractory SE (RSE). ${ }^{3}$

The cause of CSE differs with age, in adults change and/or non-compliance to anti-epileptic medications accounts for the majority of the patients, however in elderly, cerebrovascular accident (CVA) is the commonest observed etiology. ${ }^{4,5}$ Interestingly, in nearly $20 \%$ of the cases the etiology is unknown. ${ }^{6}$ In a significant number of patients with pre-existing epilepsy, no precipitating factor has been reported.

The short term mortality (at 30 days) in CSE patients is approximately $27 \% .{ }^{7,8}$ Patient age at diagnosis, severity of the etiology and duration of CSE has been shown to predict short term mortality in these patients. ${ }^{9,10}$ Additionally, longer duration of SE may aid in making it refractory to treatment. ${ }^{11}$ Importantly, early and aggressive management of CSE will improve outcome in these patients. ${ }^{12}$ Knake et al, suggested that treatment of SE can be divided into three stages, initial out of hospital, initial treatment in hospital and treatment of RSE. ${ }^{13}$

Various findings reported from large in hospital studies done in developed countries, show a variable prognosis of $\mathrm{CSE}^{14}$ with mortality ranging from $3 \%$ to $50 \%$. However similar data in developing countries is scarce or under-estimated. ${ }^{10}$ Older age and CNS infections in children have been widely accepted predictors for poor outcome in patients with CSE. ${ }^{6}$ Studies previously reported in India have been done across the spectrum of age, ${ }^{11,15-17}$ however, the adult group of the patients between the age 18 years and 60 years is less studied, possibly due to the two prong, bimodal distribution of SE in children and elderly.

However, adults form an important part of the socioeconomic chain of the society especially in developing nations. The current study therefore evaluates the outcome of adult patients with CSE, admitted into the neurointensive care unit (NICU) of a tertiary care center in South India.

\section{Materials \& methods}

A retrospective analysis of patients with CSE admitted into the NICU of Krishna Institute of Medical Sciences, a tertiary referral center in Secunderabad, India was done from December 2005 to June 2013. The inclusion criteria included patients aged 18 years and above but below 60 years. Patients with myoclonic SE, psychogenic SE, complex partial SE, absence SE, simple partial SE and those with non-convulsive SE formed the exclusion criteria.

Data collected included demographic variables, history of epilepsy, duration of epilepsy, social history, medical history, length of stay in hospital and NICU, course of stay in hospital, complications of management ${ }^{18-20}$ and mortality. The etiology of SE was grouped into acute symptomatic, remote symptomatic, idiopathic and those with pre-existing epilepsy.

\subsection{Definitions}

Status epilepticus was defined as seizures lasting for more than $5 \mathrm{~min}$ or recurrent epileptic activity over a period of more than 5 min without regain of the pre-existing level of consciousness. ${ }^{1}$ RSE was defined as SE resistant to one first line and $1 \mathrm{~s}$ line AED, requiring general anesthesia (GA). ${ }^{21}$ Super RSE was defined as SE that continues $24 \mathrm{~h}$ or more after the onset of anesthesia, including those cases in which the SE recurs on the reduction or withdrawal of anesthesia. ${ }^{22,23}$ If SE recurred days after withdrawal of anesthetic drugs and warranted re-administration of similar drugs, the length of the NICU stay included the seizure free days too.

\subsubsection{Acute symptomatic}

$\mathrm{SE}$ in the setting of an acute medical or neurological illness.

\subsubsection{Remote symptomatic}

SE resulting from past conditions resulting in a static encephalopathy or an antecedent insult such as stroke.

\subsubsection{Pre-existing epilepsy}

Known patients of epilepsy with or without AED compliance.

\subsubsection{Idiopathic or undetermined}

SE due to conditions presumed to be symptomatic, but the cause is unclear. ${ }^{24}$

\subsection{Treatment}

All the patients were treated according to established guidelines. $^{22}$ The initial treatment included benzodiazepines (diazepam or lorazepam or midazolam) followed by intravenous AEDs (phenytoin, phenobarbitone, sodium valproate or levetiracetam alone or in combination). For GA drugs used included thiopental, midazolam or propofol infusion. Support with mechanical ventilation was provided whenever necessary. ${ }^{25,26}$ The study was approved by the institutional ethics committee. 


\subsection{Complications}

Sepsis was defined as infection plus systemic manifestations of infection. Sepsis plus sepsis-induced organ dysfunction or tissue hypoperfusion was considered as severe sepsis. ${ }^{27}$ Acute kidney injury (AKI) was defined as increase in Serum Creatinine by $\geq 0.3 \mathrm{mg} / \mathrm{dl}$ within $48 \mathrm{~h}$; or Increase in Serum Creatinine to $\geq 1.5$ times baseline, which is known or presumed to have occurred within the prior 7 days; or Urine volume $<0.5 \mathrm{ml} / \mathrm{kg} / \mathrm{h}$ for $6 \mathrm{~h} .{ }^{28}$ Acute hepatic failure was described as the development of severe acute liver injury with encephalopathy and impaired synthetic function (INR of $\geq 1.5$ ) in a patient without cirrhosis or pre-existing liver disease. ${ }^{29}$

\section{Statistical analysis}

The entire cohort was divided into two groups, alive and dead at the end of stay in NICU. The differences between the groups were analyzed using chi-square test for categorical variables and unpaired students $t$ test for continuous variables. Spearman correlations were used to analysis association between the variables and mortality, where $r>0.3$ and $p<0.05$ were considered significant. Odds ratio for relative risk for mortality was performed across the four main etiological groups. All the variables which showed significant correlation with mortality were included for a step wise linear regression analysis to assess predictors of mortality where, $\beta>0.300 ; p<0.05$ were considered significant predictors. Statistical Package for Social Sciences (SPSS, ver. 17.0, IBM computers, Illinois, Chicago, USA) was used for statistical analysis.

\section{Results}

A total of 105 patients included for analysis, 40\% (42) patients were women. The mean age of the study population was $33.25 \pm 11.75$ years. One third (35) of the patients had past history of seizures. On further analysis, 36.1\% (38) of the patients progressed to RSE; the overall mortality in the study population was $19 \%(20)$.

\subsection{Etiology}

Sixty one patients (58\%) had acute symptomatic etiology, whereas remote symptomatic etiology was observed in $14.2 \%$ (15) patients. While $17.1 \%$ (18) of patients were known epileptics, the remaining $10.5 \%$ (11) patients constituted the idiopathic etiology group. Amongst the acute symptomatic group, 5 patients had alcohol withdrawal as etiology, 21 patients had vascular etiology, while 33 patients had infections of central nervous system (7 patients CNS Tuberculosis, 17 patients had encephalitis, neurocysticercosis was found in 6 patients, while 2 patients had ADEM, 1 patients had auto immune encephalitis) and two had metabolic etiology. The distribution of the etiologies across the study population is summarized in Table 1.
Table 1 - Distribution of etiology across the study population.

Etiology

Number of patients

Acute symptomatic etiology $(n=61)$

Alcohol withdrawal

Vascular etiology

Metabolic etiology

Infections of central nervous system

Remote symptomatic etiology $(n=15)$

Vascular etiology

Focal cerebral calcification

Gliosis

Idiopathic etiology $(n=11)$

Withdrawal of anti-epileptic drug $(n=18)$

\subsection{Clinical course}

In the entire cohort of 105 patients, the average length of stay in NICU was $5.25 \pm 7.62$ days. In approximately $36.1 \%$ (38) of patients, SE was refractory to medical management and hence was categorized as RSE. Mechanical ventilation was required in $45.7 \%$ (48) patients, with most of those who required mechanical ventilation being patients with RSE (38 out of 48). Seventeen percentage (18 patients) of the entire population had fever whereas severe sepsis was observed in $7.6 \%$ (8) patients. One third $(66.6 \%, 70$ out of 105$)$ of the entire population were independent for activities of daily living at discharge from the NICU, while $12.4 \%$ (13) patients required assistance for daily chores, $1.9 \%$ (2) patients. The observed mortality in the entire cohort was $19 \%(20)$.

\subsection{Mortality/outcome analysis}

A comparison of the study variables between patients who died and those alive (Table 1), showed that a significantly lower number of patients who died had past history of seizures $(15.0 \%$ vs $37.6 \% ; p=0.043)$. Similarly, acute symptomatic etiology ( $85.0 \%$ vs $51.8 \% ; p=0.041)$ was more common in patients who died in NICU, a detailed comparison of mortality across the various etiology groups in summarized in Table 2. Importantly, acute symptomatic etiology increased the odds of death 5.28 times (95\% confidence interval (CI): $1.44-19.35)(p=<0.01)$. RSE accounted for $80 \%$ (16) of the deaths. Moreover, all the complication associated with mechanical ventilation like severe sepsis, acidosis, were significantly higher in patients who died in NICU, as summarized in Table 2.

On further analyses for factors associated with mortality, etiology failed to show strong correlations with mortality $(r<0.300)$. On the contrary, RSE showed significant and strong correlation with mortality $(r=0.392 ; p<0.0001)$. Furthermore, all the complication related with prolonged mechanical ventilation, showed significant and strong correlation with mortality, summarized in Table 3. However, regression analysis for predictors of mortality in the study population showed that none of the factors were significant predictors of mortality. 
Table 2 - Comparison for demographic and clinical variables between alive and dead patients.

\begin{tabular}{|c|c|c|c|}
\hline Variable & $\begin{array}{c}\text { Alive } \\
\text { patients ( } n \text { 85) }\end{array}$ & $\begin{array}{l}\text { Dead } \\
\text { patients (n 20) }\end{array}$ & $p$ Value \\
\hline Female & $37.6 \%(32)$ & $50 \%(10)$ & 0.222 \\
\hline Age (years) & $33.5 \pm 11.7$ & $32.1 \pm 12.0$ & 0.638 \\
\hline $\begin{array}{l}\text { Past history of } \\
\text { seizures }\end{array}$ & $37.6 \%(32)$ & $15.0 \%(3)$ & 0.043 \\
\hline $\begin{array}{l}\text { Acute symptomatic } \\
\text { etiology }\end{array}$ & $51.8 \%(44)$ & $85.0 \%(17)$ & 0.041 \\
\hline $\begin{array}{l}\text { Remote symptomatic } \\
\text { etiology }\end{array}$ & $15.3 \%(13)$ & $10.0 \%(2)$ & 0.517 \\
\hline Idiopathic etiology & $12.9 \%(11)$ & $0.0 \%(0)$ & 0.118 \\
\hline $\begin{array}{l}\text { Anti-epileptic drug } \\
\text { withdrawal }\end{array}$ & $20.0 \%(17)$ & $5.0 \%(1)$ & 0.297 \\
\hline $\begin{array}{l}\text { Refractory status } \\
\text { epilepticus }\end{array}$ & $27.1 \%(23)$ & $70.0 \%(15)$ & $<0.0001$ \\
\hline Fever & $5.9 \%(5)$ & $65 \%(13)$ & $<0.0001$ \\
\hline Severe sepsis & $3.5 \%(3)$ & $25 \%(5)$ & 0.006 \\
\hline Acute kidney injury & $0 \%(0)$ & $15 \%(3)$ & 0.006 \\
\hline Hepatic failure & $0 \%(0)$ & $15 \%(3)$ & 0.006 \\
\hline Acidosis & $2.4 \%(2)$ & $35 \%(7)$ & $<0.0001$ \\
\hline HIE & $0 \%(0)$ & $25 \%(5)$ & $<0.0001$ \\
\hline $\begin{array}{l}\text { Requirement for } \\
\text { mechanical } \\
\text { ventilation }\end{array}$ & $34.1 \%(29)$ & $95 \%(19)$ & $<0.0001$ \\
\hline $\begin{array}{l}\text { Duration in } \\
\text { neurointensive } \\
\text { care unit }\end{array}$ & $4.5 \pm 6.1$ & $8.6 \pm 11.5$ & 0.028 \\
\hline
\end{tabular}

\section{Discussion}

The current study with an exclusive cohort of adult patients with CSE is the first of its kind in India, to evaluate the clinical characteristics and outcome in these patients. The findings of the current study suggest that acute symptomatic etiology makes an important contribution not only in making CSE refractory to treatment, but also in determining the outcome in these patients. The implications for clinical practice are that possibly aggressive management of the underlying etiology may help improve clinical outcome in these patients.

Studies looking at the entire spectrum of age from children to elderly, have previously reported an incidence of $20 \%$ for idiopathic etiology, however, in the current study, we observed that only $10.5 \%$ of the entire cohort had an undetermined etiology. ${ }^{30}$ In concordance to previously reported

Table 3 - Correlation of study variables with mortality in the study population ( $n=105)$.

\begin{tabular}{lcc} 
Variable & $\begin{array}{c}\text { Correlation } \\
(r) \text { value }\end{array}$ & $p$ Value \\
\hline Refractory status epilepticus & 0.392 & $<0.0001$ \\
Fever & 0.616 & $<0.0001$ \\
Severe sepsis & 0.318 & $<0.0001$ \\
Acute kidney injury & 0.354 & $<0.0001$ \\
Hepatic failure & 0.354 & $<0.0001$ \\
Acidosis & 0.458 & $<0.0001$ \\
HIE & 0.461 & $<0.0001$ \\
Requirement for mechanical ventilation & 0.480 & $<0.0001$ \\
Duration on mechanical ventilation & 0.506 & $<0.0001$ \\
\hline
\end{tabular}

studies, ${ }^{31}$ infections of central nervous system, contributed to one third of the overall etiology. Importantly, the current study reinforces that fact that acute symptomatic etiology and CNS infections continue to significantly increase the risk of mortality. ${ }^{32-35}$ Studies previously done reported that longer duration of SE predicts treatment response in these patients, ${ }^{11}$ but the retrospective design of the study restrained us from ascertaining the duration of SE prior to presentation to the hospital. Also the current study did not aim at looking at the predictors of RSE.

While acute symptomatic etiology increased the risk of mortality; the overall mortality in this study group of adult patients $(19 \%)$ is low in comparison to mortality reported by large scale studies elsewhere previously, ${ }^{36}$ probably due to improved management of CSE patients over the last decade. This may probably be due to lesser severe etiology which in turn may be due to better immunity in the adults when compared to children and elderly. This statement is encouraged by our findings that only $7.6 \%$ of the study population developed infections and subsequent spiral of events. In the entire population, more than two thirds of the patients were independent for activities of daily living (ADL), which is encouraging for the treating physician to continue optimal management in these patients.

In concordance to existing literature,$^{21}$ more than one third of the study population progressed to RSE; furthermore, a significant percentage of these patients had a poor outcome, suggesting that irrespective of age group, RSE patients have a poor prognosis. Our findings that RSE is the most strongest and significant association of mortality in this group reiterates similar findings observed by researchers in children and elderly people ${ }^{37}$ with CSE. Not only is refractiveness to treatment but also the successive events like requirement for mechanical ventilation and subsequent complications also contribute towards increased mortality observed in RSE patients. Therefore, patients with RSE should be treated aggressively not only for the underlying etiology but also to prevent systemic complications due to prolonged hospital stay especially on mechanical ventilation.

\section{Strengths \& limitations}

Our study comprises of a large data of CSE patients collected from a single center. The etiological diversity suggests that the findings are plausible due to referrals from all over the state. Variation of treatment is expected in a retrospective study; however these variations might have not affected the findings of the study. Despite being a large cohort of CSE patients, our findings may have been under powered to detect few associations. Due to the retrospective nature of the study, duration of SE prior to admission to the hospital could not be obtained.

\section{Conclusion}

We conclude that adult patients with CSE differ from the children and elderly; where in the mortality rate among adults with CSE is lower than other age groups. The prevalence of RSE and its related mortality is similar to those reported in 
children, elderly and a mixture of population. Moreover, acute symptomatic etiology, is not only the most prevalent etiology but also increases the risk of mortality in adults patients with CSE. Aggressive management of the underlying etiology and preventing CSE to progress to RSE may help improve outcome in these patients, however, further research is required in this direction.

\section{Conflicts of interest}

\section{All authors have none to declare.}

\section{R E F E R E N C E S}

1. Lowenstein DH, Bleck T, Macdonald RL. It's time to revise the definition of status epilepticus. Epilepsia. 1999 Jan;40: 120-122.

2. Chin RF, Neville BG, Scott RC. A systematic review of the epidemiology of status epilepticus. Eur J Neurol. 2004 Dec;11:800-810.

3. Holtkamp M. Treatment strategies for refractory status epilepticus. Curr Opin Crit Care. 2011 Apr;17:94-100.

4. DeLorenzo RJ, Towne AR, Pellock JM, Ko D. Status epilepticus in children, adults, and the elderly. Epilepsia. 1992;33:S15-S25.

5. Vignatelli L, Tonon C, D'Alessandro R. Incidence and shortterm prognosis of status epilepticus in adults in Bologna, Italy. Epilepsia. 2003 Jul;44:964-968.

6. Brophy GM, Bell R, Claassen J, et al. Guidelines for the evaluation and management of status epilepticus. Neurocrit Care. 2012 Aug;17:3-23.

7. Logroscino G, Hesdorffer DC, Cascino G, Annegers JF, Hauser WA. Short-term mortality after a first episode of status epilepticus. Epilepsia. 1997 Dec;38:1344-1349.

8. Hui AC, Joynt GM, Li H, Wong KS. Status epilepticus in Hong Kong Chinese: aetiology, outcome and predictors of death and morbidity. Seizure. 2003 Oct;12:478-482.

9. Wu YW, Shek DW, Garcia PA, Zhao S, Johnston SC. Incidence and mortality of generalized convulsive status epilepticus in California. Neurology. 2002 Apr 9;58:1070-1076.

10. Garzon E, Fernandes RM, Sakamoto AC. Analysis of clinical characteristics and risk factors for mortality in human status epilepticus. Seizure. 2003 Sep;12:337-345.

11. Murthy JM, Jayalaxmi SS, Kanikannan MA. Convulsive status epilepticus: clinical profile in a developing country. Epilepsia. 2007 Dec;48:2217-2223.

12. Kalviainen R. Status epilepticus treatment guidelines. Epilepsia. 2007;48:99-102.

13. Knake S, Hamer HM, Rosenow F. Status epilepticus: a critical review. Epilepsy Behav. 2009 May;15:10-14.

14. Aminoff MJ, Simon RP. Status epilepticus. Causes, clinical features and consequences in 98 patients. Am J Med. 1980 Nov;69:657-666.

15. Kalita J, Nair PP, Misra UK. A clinical, radiological and outcome study of status epilepticus from India. J Neurol. 2010 Feb;257:224-229.

16. Tripathi M, Vibha D, Choudhary N, et al. Management of refractory status epilepticus at a tertiary care centre in a developing country. Seizure. 2010 Mar;19:109-111.

17. Misra UK, Kalita J, Nair PP. Status epilepticus in central nervous system infections: an experience from a developing country. Am J Med. 2008 Jul;121:618-623.
18. Mehta RL, Kellum JA, Shah SV, et al. Acute Kidney Injury Network: report of an initiative to improve outcomes in acute kidney injury. Crit Care. 2007;11:R31.

19. Lucey MR, Brown KA, Everson GT, et al. Minimal criteria for placement of adults on the liver transplant waiting list: a report of a national conference organized by the American Society of Transplant Physicians and the American Association for the Study of Liver Diseases. Liver Transpl Surg. 1997 Nov;3:628-637.

20. Dellinger RP, Levy MM, Carlet JM, et al. Surviving Sepsis Campaign: international guidelines for management of severe sepsis and septic shock: 2008. Intensive Care Med. 2008 Jan;34:17-60.

21. Mayer SA, Claassen J, Lokin J, Mendelsohn F, Dennis LJ, Fitzsimmons BF. Refractory status epilepticus: frequency, risk factors, and impact on outcome. Arch Neurol. 2002 Feb;59:205-210.

22. Shorvon S. Super-refractory status epilepticus: an approach to therapy in this difficult clinical situation. Epilepsia. 2011 Oct;52:53-56.

23. Shorvon S, Ferlisi M. The outcome of therapies in refractory and super-refractory convulsive status epilepticus and recommendations for therapy. Brain. 2012 Aug;135:2314-2328.

24. Guidelines for epidemiologic studies on epilepsy. Commission on epidemiology and prognosis, international League against epilepsy. Epilepsia. 1993 Jul-Aug;34:592-596.

25. Esteban A, Anzueto A, Alia I, et al. How is mechanical ventilation employed in the intensive care unit? an international utilization review. Am J Respir Crit Care Med. 2000 May;161:1450-1458.

26. Amato MB, Barbas CS, Medeiros DM, et al. Effect of a protective-ventilation strategy on mortality in the acute respiratory distress syndrome. N Engl J Med. 1998 Feb 5;338:347-354.

27. Levy MM, Fink MP, Marshall JC, et al. 2001 SCCM/ESICM/ ACCP/ATS/SIS international sepsis definitions conference. Crit Care Med. 2003 Apr;31:1250-1256.

28. Kellum JA, Lameire N. Diagnosis, evaluation, and management of acute kidney injury: a KDIGO summary (Part 1). Crit Care. 2013 Feb 4;17:204.

29. Lee WM, Stravitz RT, Larson AM. Introduction to the revised American Association for the Study of Liver Diseases Position Paper on acute liver failure 2011. Hepatology. 2012 Mar;55:965-967.

30. DeLorenzo RJ, Pellock JM, Towne AR, Boggs JG. Epidemiology of status epilepticus. J Clin Neurophysiol. 1995 Jul;12:316-325.

31. Misra UK, Kalita J, Patel R. Sodium valproate vs phenytoin in status epilepticus: a pilot study. Neurology. $2006 \mathrm{Jul}$ $25 ; 67: 340-342$.

32. Rowan AJ, Scott DF. Major status epilepticus. A series of 42 patients. Acta Neurol Scand. 1970;46:573-584.

33. Rossetti AO, Hurwitz S, Logroscino G, Bromfield EB. Prognosis of status epilepticus: role of aetiology, age, and consciousness impairment at presentation. J Neurol Neurosurg Psychiatry. 2006 May;77:611-615.

34. Cherian A, Thomas SV. Status epilepticus. Ann Indian Acad Neurol. 2009 Jul;12:140-153.

35. Fountain NB. Status epilepticus: risk factors and complications. Epilepsia. 2000;41:S23-S30.

36. DeLorenzo RJ, Hauser WA, Towne AR, et al. A prospective, population-based epidemiologic study of status epilepticus in Richmond, Virginia. Neurology. 1996 Apr;46:1029-1035.

37. Towne AR, Pellock JM, Ko D, DeLorenzo RJ. Determinants of mortality in status epilepticus. Epilepsia. 1994 Jan-Feb;35:27-34. 